\title{
Structural Investigation of Rapidly Quenched FeCoPtB Alloys
}

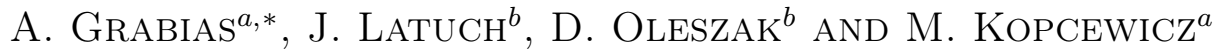 \\ ${ }^{a}$ Institute of Electronic Materials Technology, Wólczyńska 133, 01-919 Warsaw, Poland \\ ${ }^{b}$ Faculty of Materials Science and Engineering, Warsaw University of Technology \\ Wołoska 141, 02-507 Warsaw, Poland
}

\begin{abstract}
Two sets of $\mathrm{Fe}_{52-x} \mathrm{Co}_{x} \mathrm{Pt}_{28} \mathrm{~B}_{20}\left(x=0-26\right.$ at.\%) and $\mathrm{Fe}_{60-x} \mathrm{Co}_{x} \mathrm{Pt}_{25} \mathrm{~B}_{15}(x=0-40$ at.\%) alloys were prepared in the form of ribbons by the rapid quenching technique. Structure of the samples was characterized by Mössbauer spectroscopy and X-ray diffraction. In the as-quenched alloys the amorphous phase coexisted with the fcc- $(\mathrm{Fe}, \mathrm{Co}) \mathrm{Pt}$ disordered solid solution. Differential scanning calorimetry measurements performed in the range $50-720{ }^{\circ} \mathrm{C}$ revealed one or two exothermal peaks. The magnetically hard ordered $\mathrm{L} 1_{0}(\mathrm{Fe}, \mathrm{Co}) \mathrm{Pt}$ and magnetically soft $(\mathrm{Fe}, \mathrm{Co})_{2} \mathrm{~B}$ nanocrystalline phases were formed due to thermal treatment of the alloys. The influence of Co content on the structure of the as-quenched and heated alloys was studied.
\end{abstract}

PACS: $75.50 . \mathrm{Bb}, 75.50 . \mathrm{Kj}, 76.80 .+\mathrm{y}$

\section{Introduction}

Nanostructured Fe-Pt-B alloys, consisting of hard and soft magnetic phases, have revealed excellent hard magnetic properties [1-5]. Such materials can be used as efficient exchange-coupled spring magnets. In Fe-Pt-B alloys the ordered tetragonal $\mathrm{L}_{0} \mathrm{FePt}$ serves as the hard magnetic phase whereas the $\mathrm{Fe}_{2} \mathrm{~B}$ compound plays a role of magnetically soft component. Such nanocomposite structures can be formed directly by rapid quenching $[4$, $5]$ or by annealing of disordered alloys [1-3]. It is also known that the ordered $\mathrm{L} 1_{0} \mathrm{CoPt}$ phase reveals a high magnetocrystalline anisotropy similar to that of the $\mathrm{L} 1_{0}$ $\mathrm{FePt}$ one. However, the $\mathrm{L} 1_{0} \mathrm{CoPt}$ phase has a significantly lower temperature of the order-disorder transformation than that of the $\mathrm{L} 1_{0} \mathrm{FePt}$ phase. Recently, few works devoted to Co-containing Fe-Pt-B alloys have been published $[5,6]$.

In the present work, the effect of Co substitution for $\mathrm{Fe}$ on the formation and thermal stability of rapidly quenched Fe-Co-Pt-B alloys was studied. Structural characterization of the Fe-Co-Pt-B alloys was performed using Mössbauer spectroscopy and X-ray diffraction methods. Mössbauer spectroscopy has been successfully applied in the study of Fe-Pt [7-9] and Fe-Pt-B [10-13] magnetic systems.

\section{Experimental details}

$\mathrm{Fe}_{52-x} \mathrm{Co}_{x} \mathrm{Pt}_{28} \mathrm{~B}_{20} \quad(x=0-26 \quad$ at. $\%)$ and $\mathrm{Fe}_{60-x} \mathrm{Co}_{x} \mathrm{Pt}_{25} \mathrm{~B}_{15}(x=0-40$ at.\%) alloys were prepared in the form of ribbons by the rapid quenching technique using a single roller melt spinning device under an $\mathrm{Ar}$ protective atmosphere. The linear velocity of $45 \mathrm{~m} / \mathrm{s}$ at the spinning wheel was applied. The ribbons were about $1 \mathrm{~mm}$ wide and $15-20 \mu \mathrm{m}$ thick. Differential scanning calorimetry (DSC) measurements were performed for

\footnotetext{
* corresponding author; e-mail: agrabias@itme.edu.pl
}

the as-quenched alloys in the range $50-720{ }^{\circ} \mathrm{C}$ with the heating rate of $40{ }^{\circ} \mathrm{C} / \mathrm{min}$. Structural properties of the as-quenched and heated ribbons were investigated by Mössbauer spectroscopy and X-ray diffraction (XRD) with $\mathrm{CuK}_{\alpha}$ radiation. All Mössbauer spectra were measured in transmission geometry at room temperature. A constant-acceleration spectrometer with a ${ }^{57} \mathrm{Co}$-in-Rh source with activity of about $25 \mathrm{mCi}$ was used. Mössbauer spectra were fitted using the NORMOS program [14]. The spectra of the as-quenched alloys were fitted with a hyperfine field distribution $P\left(B_{h f}\right)$ method. The histogram method of Hesse and Rübartsch with constrains introduced by LeCaër and Dubois was used $[15,16]$. A linear correlation between the isomer shift and the hyperfine field was assumed in order to account for the asymmetry of the hyperfine-split spectra. The spectra of fully crystalline samples were analyzed using the least squares method, assuming Lorentzian profile of lines. Relative fractions of the spectral components related to identified phases were calculated as a ratio of the area of the relevant subspectrum to the total spectral area, assuming similar Debye-Waller factors for each phase. Isomer shifts are given with respect to $\alpha$-Fe standard.

\section{Results}

Mössbauer spectra of the rapidly quenched $\mathrm{Fe}_{52-x} \mathrm{Co}_{x} \mathrm{Pt}_{28} \mathrm{~B}_{20}$ and $\mathrm{Fe}_{60-x} \mathrm{Co}_{x} \mathrm{Pt}_{25} \mathrm{~B}_{15}$ alloys are shown in Fig. 1 and Fig. 2, respectively. The spectra consist of broad magnetic hyperfine structures characteristic of disordered ferromagnetic alloys. All spectra were fitted with hyperfine field distribution, $P\left(B_{h f}\right)$, method (solid lines in Figs. 1-2). The corresponding $P\left(B_{h f}\right)$ distributions are presented together with the transmission spectra. The Mössbauer spectra of $\mathrm{Fe}_{52-x} \mathrm{Co}_{x} \mathrm{Pt}_{28} \mathrm{~B}_{20}$ ribbons resemble spectra of Fe-based amorphous alloys (Fig. 1). The broad $P\left(B_{h f}\right)$ distributions indicate a variety of local atomic $\mathrm{Fe}$ environments in the amorphous structure. The main peak at about 
$28 \mathrm{~T}$ (for $x=0$ ) is attributed to the disordered Fe-Pt regions, as it was reported earlier [12, 13]. This peak shifts slightly towards lower $B_{h f}$ values with increasing Co content (26 $\mathrm{T}$ for $x=26$ ). The shoulder at about $20 \mathrm{~T}$ can be assigned to amorphous (Fe,Co)-B regions. The minor peak at about 11-12 $\mathrm{T}$ originates from $\mathrm{FeB}$ environments [12, 13]. The average values calculated from the entire hyperfine field distributions are in the range $23-24 \mathrm{~T}$ for all compositions.

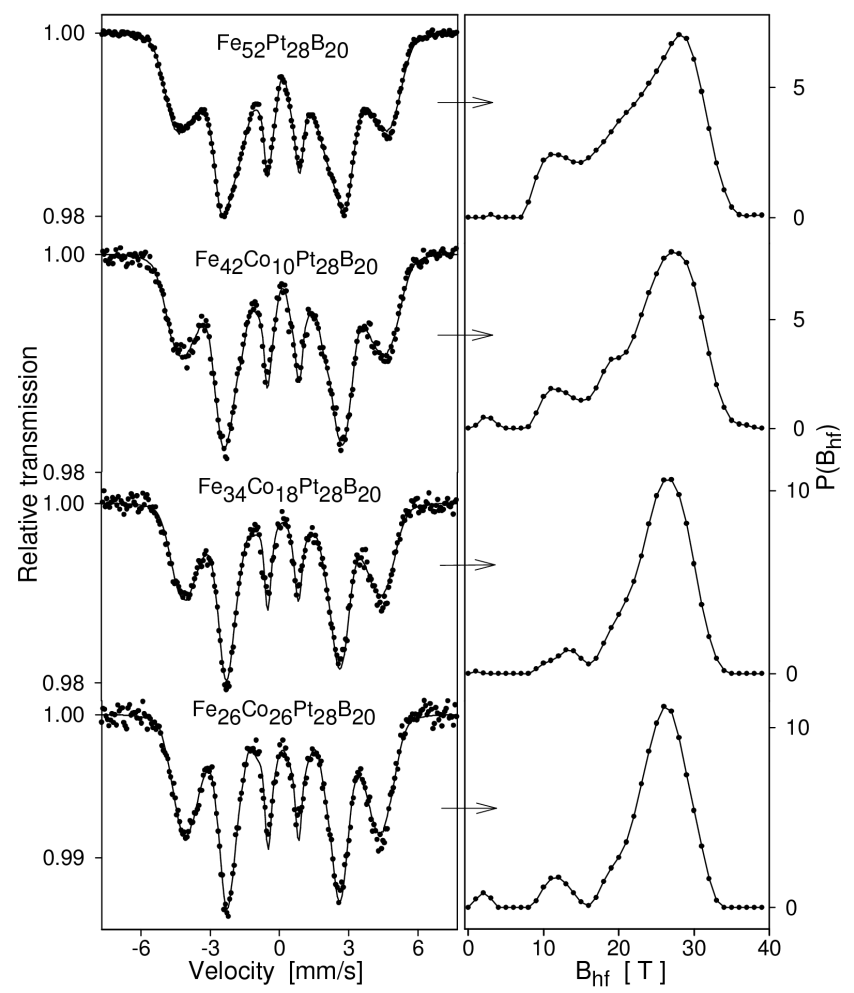

Fig. 1. Mössbauer spectra and the corresponding hyperfine field distributions $P\left(B_{h f}\right)$ of as-quenched $\mathrm{Fe}_{52-x} \mathrm{Co}_{x} \mathrm{Pt}_{28} \mathrm{~B}_{20}$ alloys.

The Mössbauer spectra of $\mathrm{Fe}_{60-x} \mathrm{Co}_{x} \mathrm{Pt}_{25} \mathrm{~B}_{15}$ alloys (Fig. 2) are characterized by larger hyperfine fields and narrower lines than in the previous case (Fig. 1). The main peak in $P\left(B_{h f}\right)$ distributions is fairly narrow (Fig. 2). The dominating peak in $P\left(B_{h f}\right)$ distribution at about 29-30 $\mathrm{T}$ for $x=0$ has its maximum at $31 \mathrm{~T}$ for Co-containing alloys, indicating a formation of the fcc-(Fe, $\mathrm{Co}) \mathrm{Pt}$ disordered solid solution [8-13]. The shoulder observed at about $23 \mathrm{~T}$ for $x=0$ is attributed to amorphous regions with a composition close to $\mathrm{Fe}_{2} \mathrm{~B}[12,13]$. For larger $\mathrm{Co}$ content its maximum shifts to lower hyperfine fields $(20-21 \mathrm{~T}$ for $x=40)$. The minor peak at about $12 \mathrm{~T}$ is much less pronounced than for the previous set of alloys (Fig. 1). The calculated average value of $B_{h f}$ increases from $26.0 \mathrm{~T}$ for $x=0$ to $28.2 \mathrm{~T}$ for $x=40$. The larger $B_{h f}$ values and significantly smaller width of $P\left(B_{h f}\right)$ distributions indicate that abundance of the amorphous component in rapidly quenched
$\mathrm{Fe}_{60-x} \mathrm{Co}_{x} \mathrm{Pt}_{25} \mathrm{~B}_{15}$ alloys is substantially smaller than in $\mathrm{Fe}_{52-x} \mathrm{Co}_{x} \mathrm{Pt}_{28} \mathrm{~B}_{20}$. The latter finding may be related to differences in boron content. Boron presence usually increases glass forming ability of Fe-based alloys.

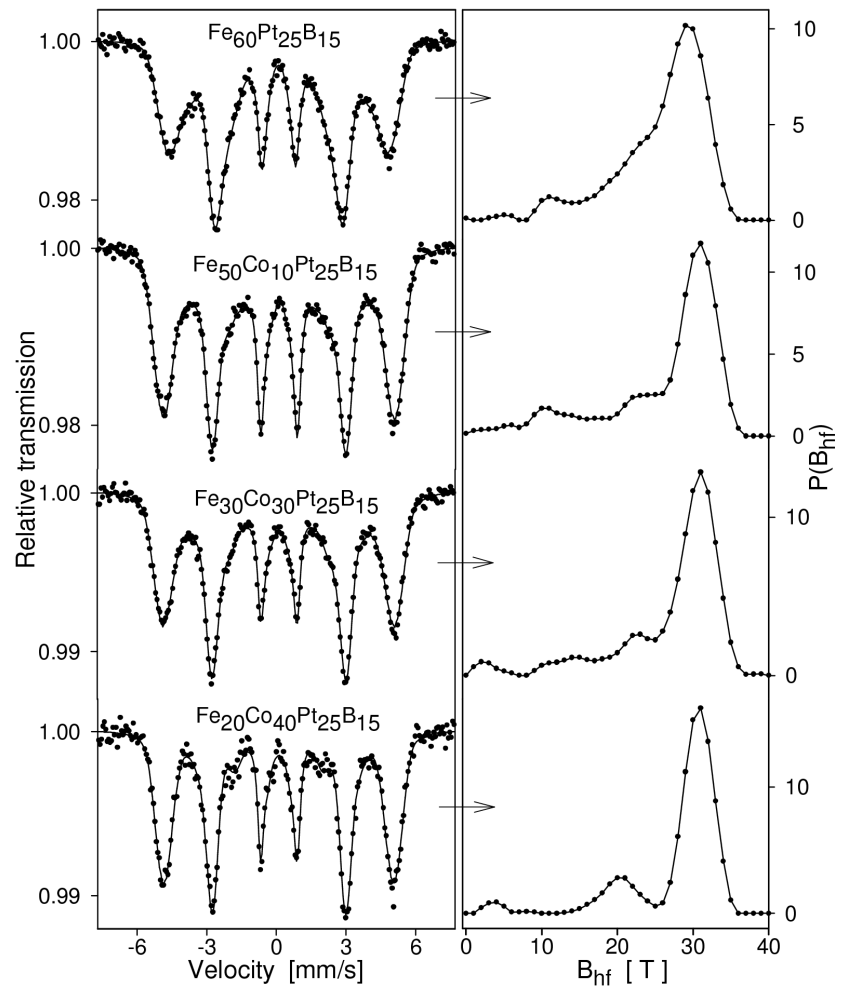

Fig. 2. Mössbauer spectra and the corresponding hyperfine field distributions $P\left(B_{h f}\right)$ of as-quenched $\mathrm{Fe}_{60-x} \mathrm{Co}_{x} \mathrm{Pt}_{25} \mathrm{~B}_{15}$ alloys.

XRD patterns of the as-quenched $\mathrm{Fe}_{52-x} \mathrm{Co}_{x} \mathrm{Pt}_{28} \mathrm{~B}_{20}$ and $\mathrm{Fe}_{60-x} \mathrm{Co}_{x} \mathrm{Pt}_{25} \mathrm{~B}_{15}$ alloys are presented in Fig. 3 and Fig. 4, respectively. Diffraction patterns obtained for the first set of the alloys consist of a broad "halo", originating from the amorphous phase, superimposed on the peak at about $41^{\circ}$, belonging to the disordered fcc(Fe,Co)Pt solid solution (Fig. 3). The "halo" is clearly seen especially for larger Co content $(x=18$ and $x=26)$, indicating that these ribbons are predominantly amorphous. For the alloys with $x=0$ and $x=10$ also less intense diffraction peaks related to the nanocrystalline fcc phase are detected. Well-defined diffraction peaks in Fig. 4, observed for all $\mathrm{Fe}_{60-x} \mathrm{Co}_{x} \mathrm{Pt}_{25} \mathrm{~B}_{15}$ alloys, correspond to the nanocrystalline fcc- $(\mathrm{Fe}, \mathrm{Co}) \mathrm{Pt}$ phase. Average crystallite sizes estimated using the Scherrer formula are below $15 \mathrm{~nm}$. Traces of a broad peak observed at about $45^{\circ}$ can be attributed to amorphous regions with a composition around $(\mathrm{Fe}, \mathrm{Co})_{2} \mathrm{~B}$, in good agreement with the Mössbauer results (Fig. 2).

The Mössbauer and XRD results have shown that the rapidly quenched FeCoPtB alloys have inhomogeneous structures consisting of a mixture of the amorphous phase and the fcc- $(\mathrm{Fe}, \mathrm{Co}) \mathrm{Pt}$ disordered solid so- 


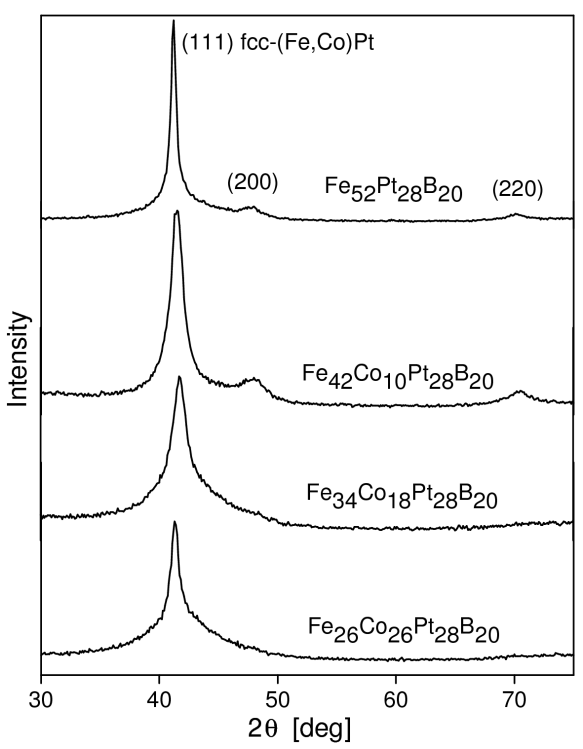

Fig. 3. XRD patterns of as-quenched $\mathrm{Fe}_{52-x} \mathrm{Co}_{x} \mathrm{Pt}_{28} \mathrm{~B}_{20}$ alloys.

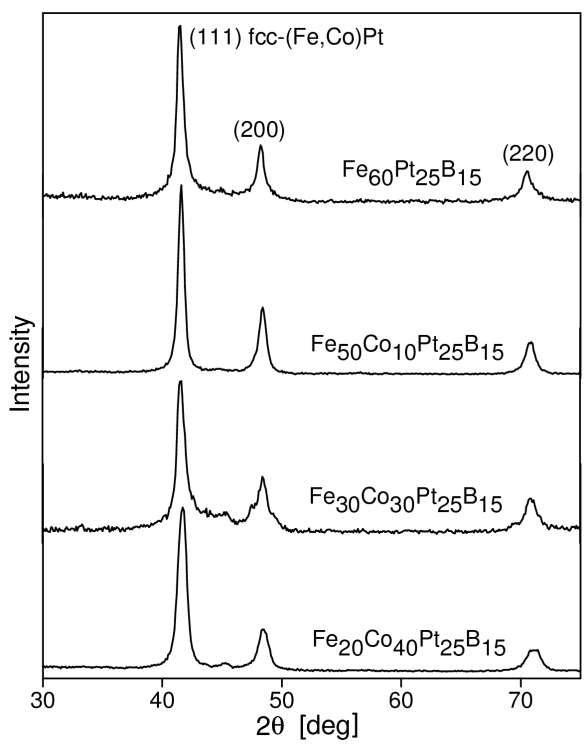

Fig. 4. XRD patterns of as-quenched $\mathrm{Fe}_{60-x} \mathrm{Co}_{x} \mathrm{Pt}_{25} \mathrm{~B}_{15}$ alloys.

lution. The $\mathrm{Fe}_{52-x} \mathrm{Co}_{x} \mathrm{Pt}_{28} \mathrm{~B}_{20}$ alloys are predominantly amorphous. It seems that in this case Co addition enhances glass forming ability. The increase of Co concentration in the alloys decreases the hyperfine field of the amorphous phase. In the $\mathrm{Fe}_{60-x} \mathrm{Co}_{x} \mathrm{Pt}_{25} \mathrm{~B}_{15}$ alloys the nanocrystalline fcc- $(\mathrm{Fe}, \mathrm{Co}) \mathrm{Pt}$ phase coexists with amorphous (Fe, Co)-B regions. A decrease of the hyperfine field related to amorphous $(\mathrm{Fe}, \mathrm{Co})_{2} \mathrm{~B}$ environments was observed with the increase of Co content.

Thermal stability of the FeCoPtB alloys was studied by DSC measurements. Examples of DSC curves are presented in Fig. 5. For all samples studied one or two exothermal peaks are observed. The weak peak at lower temperatures obtained for $\mathrm{Fe}_{52-x} \mathrm{Co}_{x} \mathrm{Pt}_{28} \mathrm{~B}_{20}$ alloys can be related to thermally induced atomic rearrangements in the amorphous phase, leading to a formation of the fcc(Fe,Co)Pt phase. The onset temperature of this peak increases with increasing Co content from $378^{\circ} \mathrm{C}$ to $413{ }^{\circ} \mathrm{C}$ for $x=0$ and $x=26$, respectively. Similar finding has been reported in [6]. The main exothermal peak, observed for all alloys studied, is attributed to the crystallization of the amorphous phase and ordering transformation of the fcc solid solution to the tetragonal ordered $\mathrm{L} 1_{0}$ phase. Onset temperatures of these structural transformations are in the range $508-583{ }^{\circ} \mathrm{C}$ and are higher for $\mathrm{Fe}_{60-x} \mathrm{Co}_{x} \mathrm{Pt}_{25} \mathrm{~B}_{15}$ alloys than for $\mathrm{Fe}_{52-x} \mathrm{Co}_{x} \mathrm{Pt}_{28} \mathrm{~B}_{20}$.

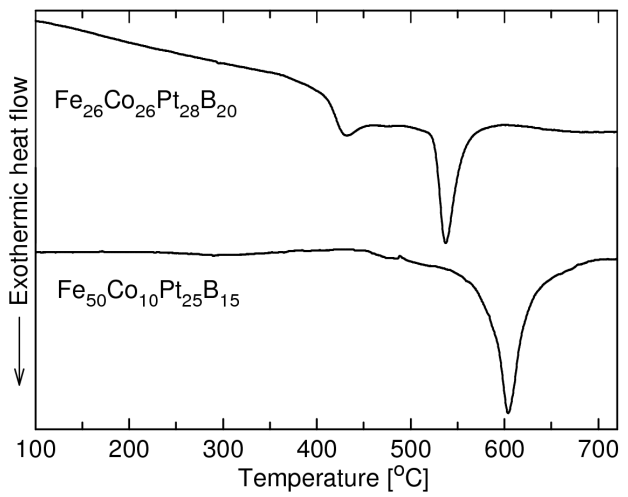

Fig. 5. Examples of DSC curves recorded for FeCoPtB ribbons at $40{ }^{\circ} \mathrm{C} / \mathrm{min}$.

In order to study thermally induced structural transformations of the FeCoPtB alloys Mössbauer spectra were recorded after DSC measurements. Examples of the spectra obtained for the $\mathrm{Fe}_{60-x} \mathrm{Co}_{x} \mathrm{Pt}_{25} \mathrm{~B}_{15}(x=0$ and $x=40$ ) samples heated up to $720{ }^{\circ} \mathrm{C}$ are shown in Fig. 6. The Mössbauer spectrum of the Co-free alloy is fitted with four magnetic components. The S1 sextet with $B_{h f}=23.6 \mathrm{~T}$, isomer shift $\delta=+0.12 \mathrm{~mm} / \mathrm{s}$ and quadrupole shift $\Delta=0.00 \mathrm{~mm} / \mathrm{s}$ is assigned to the $\mathrm{Fe}_{2} \mathrm{~B}$ compound [17]. The $\mathrm{S} 2$ sextet with $B_{h f}=$ $27.9 \mathrm{~T}, \delta=+0.27 \mathrm{~mm} / \mathrm{s}$ and $\Delta=0.29 \mathrm{~mm} / \mathrm{s}$ corresponds to the tetragonal ordered $\mathrm{L} 1_{0} \mathrm{FePt}$ phase $[9,18]$. The S3 sextet with $B_{h f}=28.8 \mathrm{~T}, \delta=+0.20 \mathrm{~mm} / \mathrm{s}$ and $\Delta=0.00 \mathrm{~mm} / \mathrm{s}$ is attributed to the untransformed fcc-FePt phase $[8,9]$. In addition to these three components a small spectral contribution of the S4 sextet with a large hyperfine field of $36.5 \mathrm{~T}, \delta=+0.23 \mathrm{~mm} / \mathrm{s}$ and $\Delta=-0.28 \mathrm{~mm} / \mathrm{s}$ is detected in the spectrum. A very similar minor spectral component was observed for the binary $\mathrm{Fe}_{61} \mathrm{Pt}_{39} \mathrm{~L}_{0}$ ordered alloy [7]. It was attributed to $\mathrm{Fe}$ atoms on Pt-sites in the $\mathrm{L}_{0}$ structure. Therefore, the S4 sextet can be assigned to ironrich FePt environments most probably in the $\mathrm{L}_{0}$ structure. The Mössbauer spectrum of the $\mathrm{Fe}_{20} \mathrm{Co}_{40} \mathrm{Pt}_{25} \mathrm{~B}_{15}$ alloy is fitted with three magnetic components (S1-S3). The hyperfine parameters of the S2 and S3 sextets are very similar to those obtained for the Co-free alloy. How- 


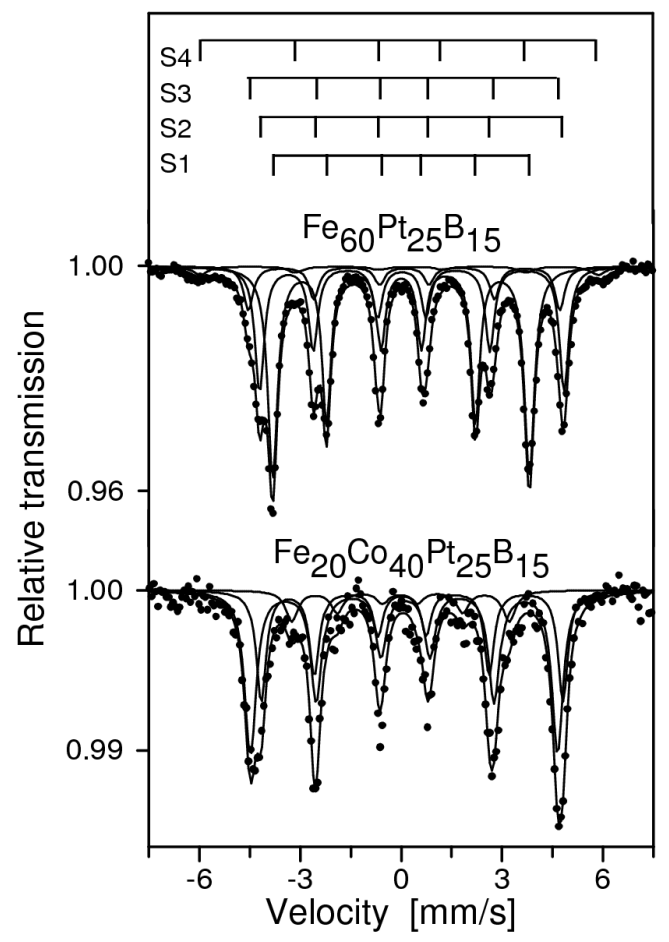

Fig. 6. Mössbauer spectra of $\mathrm{Fe}_{60-x} \mathrm{Co}_{x} \mathrm{Pt}_{25} \mathrm{~B}_{15}(x=$ 0 and $x=40$ ) samples heated up to $720{ }^{\circ} \mathrm{C}$. Positions of the subspectral lines related to the $\mathrm{Fe}_{2} \mathrm{~B}, \mathrm{~L} 1_{0} \mathrm{FePt}$, fcc-FePt and iron-rich FePt phases are marked by $\mathrm{S} 1$, $\mathrm{S} 2, \mathrm{~S} 3$ and S4, respectively.

ever, the hyperfine field value of $20.1 \mathrm{~T}$ obtained for the $(\mathrm{Fe}, \mathrm{Co})_{2} \mathrm{~B}$ phase $(\mathrm{S} 1)$ is significantly lower than that of the $\mathrm{Fe}_{2} \mathrm{~B}$ compound. Comparing the $B_{h f}$ values of the $\mathrm{S} 1$ sextet obtained for the alloys with $x=0-40$ one can conclude that the increase of Co content decreases the hyperfine field of the $(\mathrm{Fe}, \mathrm{Co})_{2} \mathrm{~B}$ phase. Furthermore, the increase of Co content causes a decrease of the relative spectral fraction of the S1 sextet from about $50 \%$ for $x=0$ to about $12 \%$ for $x=40$. The increase of the relative fraction of the S3 sextet is observed from about $13 \%$ for $x=0$ to about $54 \%$ for $x=40$. The relative contribution of the $\mathrm{S} 2$ sextet assigned to the ordered $\mathrm{L} 1_{0} \mathrm{FePt}$ phase is slightly larger for Co-containing alloys (about $34 \%$ for $x=40$ ).

\section{Conclusions}

Mössbauer spectroscopy and X-ray diffraction measurements have shown that rapidly quenched $\mathrm{Fe}_{52-x} \mathrm{Co}_{x} \mathrm{Pt}_{28} \mathrm{~B}_{20}$ alloys are predominantly amorphous. In these alloys cobalt addition enhanced glass forming ability. In $\mathrm{Fe}_{60-x} \mathrm{Co}_{x} \mathrm{Pt}_{25} \mathrm{~B}_{15}$ alloys the fcc- $(\mathrm{Fe}, \mathrm{Co}) \mathrm{Pt}$ disordered solid solution coexists with amorphous (Fe,Co)-B regions. Differential scanning calorimetry curves of the as-quenched samples revealed one or two exothermal peaks. The dominating exothermal effect was related to the crystallization of amorphous regions and to the transformation of the fcc- $(\mathrm{Fe}, \mathrm{Co}) \mathrm{Pt}$ solid solution to the ordered tetragonal (Fe, Co)Pt phase. Onset temperatures of these structural transformations are higher for $\mathrm{Fe}_{60-x} \mathrm{Co}_{x} \mathrm{Pt}_{25} \mathrm{~B}_{15}$ than for $\mathrm{Fe}_{52-x} \mathrm{Co}_{x} \mathrm{Pt}_{28} \mathrm{~B}_{20}$ alloys. The magnetically hard $\mathrm{L}_{0}$ $(\mathrm{Fe}, \mathrm{Co}) \mathrm{Pt}$ and magnetically soft $(\mathrm{Fe}, \mathrm{Co})_{2} \mathrm{~B}$ nanocrystalline phases were formed due to heating the samples up to $720{ }^{\circ} \mathrm{C}$. Cobalt addition is found to decrease the hyperfine field of the $(\mathrm{Fe}, \mathrm{Co})_{2} \mathrm{~B}$ phase.

\section{Acknowledgement}

This work was financially supported by the Ministry of Science and Higher Education (Grant No. N507 140 $32 / 4048)$.

\section{References}

[1] W. Zhang, D.V. Louzguine, A. Inoue, Appl. Phys. Lett. 85, 4998 (2004).

[2] C.W. Chang, H.W. Chang, C.H. Chiu, W.C. Chang, S.K. Chen, A.C. Sun, J. Magn. Magn. Mater. 292, 120 (2005).

[3] W. Zhang, P. Sharma, K. Shin, D.V. Louzguine, A. Inoue, Scr. Mater. 54, 431 (2006).

[4] W. Zhang, K. Yubuta, P. Sharma, A. Inoue, J. Appl. Phys. 99, 08E914 (2006).

[5] A. Makino, T. Bitoh, M. Nakagawa, J. Non-Cryst. Solids 353, 3655 (2007).

[6] A. Inoue, W. Zhang, J. Appl. Phys. 97, $10 \mathrm{H} 308$ (2005).

[7] S. Koyama, T. Goto, J. Magn. Magn. Mater. 321, 2407 (2009).

[8] P. Schaaf, K. Zhang, C. Lange, A. Holz, M. Weisheit, S. Fähler, Appl. Surf. Sci. 253, 8107 (2007).

[9] F.E. Spada, F.T. Parker, C.L. Platt, J.K. Howard, J. Appl. Phys. 94, 5123 (2003).

[10] A. Grabias, M. Kopcewicz, D. Oleszak, J. Latuch, M. Kowalczyk, M. Pękała, J. Phys. Conf. Ser. 144, 012077 (2009).

[11] A. Grabias, M. Kopcewicz, D. Oleszak, J. Latuch, M. Kowalczyk, M. Pękała, J. Phys. Conf. Ser. 200, 082007 (2010).

[12] A. Grabias, M. Kopcewicz, D. Oleszak, J. Latuch, J. Phys. Conf. Ser. 217, 012075 (2010).

[13] A. Grabias, M. Kopcewicz, D. Oleszak, J. Latuch, M. Kowalczyk, M. Pękała, J. Magn. Magn. Mater. 322, 3137 (2010).

[14] R.A. Brand, J. Lauer, D.M. Herlach, J. Phys. F: Met. Phys. 13, 675 (1983).

[15] J. Hesse, A. Rübartsch, J. Phys. E: Sci. Instrum. 7, 526 (1974).

[16] G. LeCaër, J.M. Dubois, J. Phys. E: Sci. Instrum. 12, 1083 (1979).

[17] F.H. Sanchez, J.I. Budnick, Y.D. Zhang, W.A. Hines, M. Choi, R. Hasegawa, Phys. Rev. B 34, 4738 (1986).

[18] T. Goto, H. Utsugi, A. Kashiwakura, J. Magn. Magn. Mater. 104-107, 2051 (1992). 